\title{
Torque Ripple Reduction in Sectored Multi Three-Phase Machines Based on PWM Carrier Phase Shift
}

\author{
Xuchen Wang, Student Member, IEEE, Giacomo Sala, He Zhang, Senior Member, IEEE, \\ Chunyang Gu, Member, IEEE, Giampaolo Buticchi, Senior Member, IEEE, Andrea \\ Formentini, Member, IEEE, Chris Gerada, Senior Member, IEEE, Patrick Wheeler, Senior
} Member, IEEE

\begin{abstract}
The interest in multiphase machines for high power and reliable drives has been growing, and many control algorithms have been proposed to improve their torque performance. This work presents a new approach to the modeling of a multi three-phase drive, aiming at the minimization of the torque ripple introduced by Pulse Width Modulation (PWM) voltage excitation, by the shift of carrier phase angles among different three-phase inverters. The underlying idea is to use standard three-phase converters feeding the individual segment and to apply a phase shift between the PWM carriers. For the torque ripple analyzed in this paper, only the interaction between the armature field, resulting from the PWM voltage excitation, and the fundamental component of the permanent magnet field is considered. The proposed carrier phase shift angles are obtained for a case study of sectored triple three-phase synchronous permanent magnet machine. Analytical, numerical and finite element analysis (FEA) results are presented to explain how the carrier shift angles affect the current and torque ripple. Finally, experimental results are presented to validate the model and the control algorithm.
\end{abstract}

Index Terms- Analytical models, multiphase drives, machine vector control, permanent magnet machines, pulse width modulation, torque control.

\section{NOMENCLATURE}

$N$

Number of multi three-phase systems.

$\alpha_{p}$
$\omega_{m}$
$V_{\mathrm{dc}}$
$M$
$m$
$n$
$A_{m n}$
$f_{\mathrm{c}}$
$\omega_{\mathrm{c}}$
$\omega_{\mathrm{o}}$
$\omega_{m n}$

$Z\left(\omega_{o}\right)$
$Z\left(\omega_{m n}\right)$
$\theta_{\mathrm{c}, p}$
$x_{p}(t)$
$\theta_{o}$

Manuscript received January 8, 2019; revised May 15, 2019; accepted July 6, 2019. This work was supported by China NSFC under Grant 51607099 and 51807099, and by the Ningbo Science \& Technology Beauro under Grant 2017D10029, 2017D10031 and 2013 A31012.

X. Wang, H. Zhang (corresponding author), C. Gu, and G. Buticchi are with the Key Laboratory of More Electric Aircraft Technology of Zhejiang Province, University of Nottingham Ningbo China, Ningbo 315100, China (e-mail: xuchen.wang@nottingham.edu.cn; he.zhang @nottingham.edu.cn; chunyang.gu@nottingham.edu.cn; giampaolo. buticchi@nottingham.edu.cn).

A. Formentini, C. Gerada, and P. Wheeler are with University of Nottingham, NG7 2RD, UK (e-mail: andrea.formentini@nottingham. ac.uk; chris.gerada@nottingham.ac.uk; pat.wheeler@nottingham.ac. uk).

G. Sala is with the Department of Electric, Electronic and Information Engineering "G. Marconi," University of Bologna. (e-mail: giacomo.sala5@unibo.it).
Space phase shift angle between the $p^{\text {th }}$ three-phase system and the stator reference frame [rad].

Mechanical speed of the machine [rad/s].

DC link supply voltage of each independent converter module [V].

Modulation index, $M \in[0,1]$.

Carrier signal index.

Modulating signal index.

Amplitude of the harmonic component with $m$ carrier signal index, and $n$ modulating signal index.

Frequency of the carrier signal $[\mathrm{Hz}]$.

Frequency of the carrier signal [ $\mathrm{rad} / \mathrm{s}]$.

Frequency of the modulating signal $[\mathrm{rad} / \mathrm{s}]$.

Frequency of the harmonic component with $m$ carrier signal index, and $n$ modulating signal index $[\mathrm{rad} / \mathrm{s}]$.

Impedance of the fundamental component.

Impedance of the harmonic component at the frequency of $\omega_{m n}$.

Phase angle of the carrier signal of the $p^{\text {th }}$ three-phase system [rad].

Time-varying angle of the carrier signal in the $p^{\text {th }}$ three-phase system [rad].

Phase angle of the fundamental phase voltage (modulating signal) of the first threephase system [rad].

$\theta_{0}^{\prime} \quad$ Phase angle of the fundamental phase current of the first three-phase system [rad].

$y(t) \quad$ Time-varying angle of the fundamental phase voltage (modulating signal) of the first three-phase system [rad].

$y^{\prime}(t) \quad$ Time-varying angle of the fundamental phase current of the first three-phase system [rad].

$R \quad$ Stator phase resistance [ $\Omega]$.

$L_{X}, M_{X Y} \quad$ Self and mutual phase inductances of the machine matrix $\boldsymbol{L}$ of a general machine winding, $X, Y \in\left\{\mathrm{A}_{1}, \mathrm{~B}_{1}, \mathrm{C}_{1}, \mathrm{~A}_{2}, \mathrm{~B}_{2}, \mathrm{C}_{2}, \mathrm{~A}_{3}\right.$, $\left.\mathrm{B}_{3}, \mathrm{C}_{3}\right\}$ and $X \neq Y$. 
$L, M_{1}, M_{2}, M_{3} \quad$ Self and mutual phase inductances for the representation of the inductance matrix $\boldsymbol{L}$ for the analysed winding layout.

\section{LIST OF ACRONYMS}

PWM Pulse Width Modulation

CPS-PWM Carrier-based Phase Shift Pulse Width Modulation

FEA Finite Element Analysis

PMSM Permanent Magnet Synchronous Machine

Back-EMF Back Electromotive Force

FFT Fast Fourier Transformation

\section{INTRODUCTION}

$\mathrm{M}$ ultiphase drives are well known for being a suitable solution for high power systems such as ship propulsion, electric vehicles and More Electric Aircraft applications [1]-[6]. The main advantage of a multiphase drive is the significant improvement in terms of flexibility in the design and control of the converters, and the reduced power rating requirement of the power electronic components [7]-[11]. Among the multiphase drives, the multi three-phase layout offers the possibility to obtain a multiphase system by means of commercial three-phase inverters. Furthermore, the multi three-phase layout with parallel or independent dc links offers a higher fault tolerance [12]-[15]. A scheme of a multi three-phase drive is presented in Fig. 1.

To achieve high power and high power density drives, one of the main solution is to significantly increase the speed of the machine [16]-[19]. However, in high power systems the power electronics must bear high currents (or voltages) and the switching frequency of the power semiconductor is usually limited (below $30 \mathrm{kHz}$ ) [20]-[23]. This results in significant high frequency current ripple caused by the PWM of the DC/AC converter [24], [25]. The ripple affects the performance of the machine in terms of machine copper loss and torque [24]-[26]. In particular, the introduction of high frequency torque ripple is

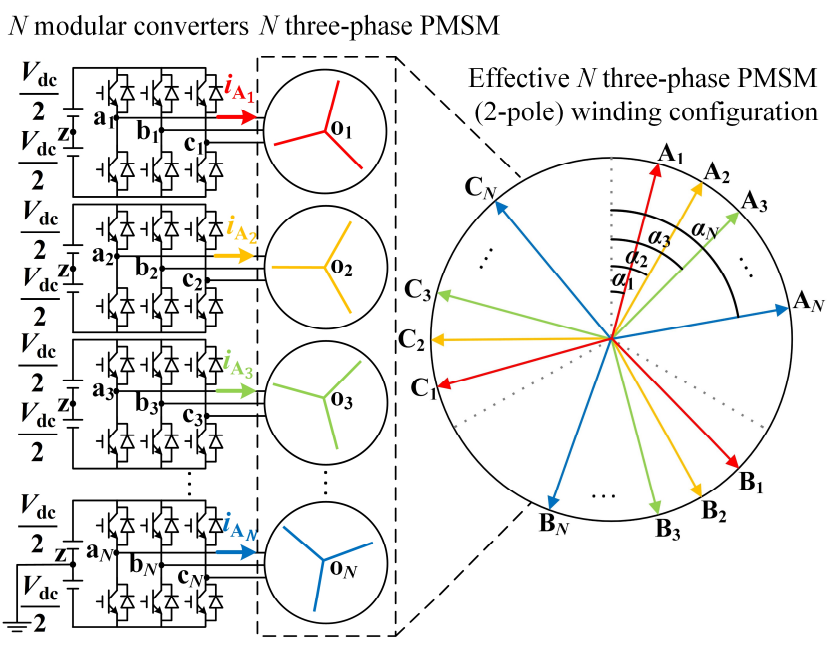

Fig. 1. $N$ three-phase drive system. source of vibrations and noise that are undesired, especially for transport applications with high reliability requirements [27][28]. The possibility of reducing the torque ripple in PWM drive systems has been validated by previous works [24], [25], [27]. For example, in [27] the authors define a technique to eliminate the vibration in a phase shifted dual three-phase machine. This paper proposes an analytical model of the torque ripple generated in a sectored multi three-phase machine fed by a PWM control of multi three-phase modular converters. Starting from the model, a method for the torque ripple reduction by applying CPS-PWM technique to the multi threephase inverters is defined. Results of analytical, numerical and FEA simulations are presented and validated by experimental tests.

In Section II, the model of the sectored multi three-phase machine is derived as well as the torque equation. Section III describes the torque ripple due to a PWM excitation. Section IV analyzes a case study of a sectored triple three-phase PMSM. Section V and VI show the simulation and experimental results. Section VII draws the conclusion.

\section{Sectored Multi Three-Phase Machine}

A sectored multi three-phase PMSM layout presents a set of three-phase windings symmetrically placed around the stator, covering one pole pair each. The advantage of this layout can be found in terms of fault tolerance and manufacturing. Indeed, the phases under one pole pair have not physical contact (overlapping) with the other phases. Therefore, the magnetic mutual coupling among phases of different windings are significantly lower than the one of other distributed winding solution [29]. The previous advantages allow for reducing the spread of faults. As example, Fig. 2 shows the triple three-phase sectored machine analyzed in this work. The model of the PWM voltage waveform applied to this machine is based on a double Fourier transformation already used in some research works on the PWM topic [30], [31]. This work aims at extending the theory to an arbitrary number of phases.

As it is shown in Fig. 1, in the equivalent 2-pole space winding structure of the $N$ three-phase systems, the space shift angles between the $p^{\text {th }}$ three-phase system $(p \in\{1, \ldots, N\})$ and the stator reference frame are represented by $\alpha_{1}, \ldots, \alpha_{N}$ respectively. In addition, the back-EMFs generated on each phase are represented by $e_{\mathrm{A}_{1}}(t), e_{\mathrm{B}_{1}}(t), e_{\mathrm{C}_{1}}(t), \ldots, e_{\mathrm{A}_{N}}(t)$, $e_{\mathrm{B}_{N}}(t), e_{\mathrm{C}_{N}}(t)$ respectively. The total back-EMF space vector related to all the $N$ three-phase systems $\vec{e}_{\text {total }}(t)$ can be represented by (1):

$$
\begin{gathered}
\vec{e}_{\text {total }}(t)=\frac{2}{3 N} \sum_{p=1}^{N}\left[e_{\mathrm{A}_{p}}(t) e^{j \alpha_{p}}\right. \\
\left.+e_{\mathrm{B}_{p}}(t) e^{j\left(\alpha_{p}+\frac{2}{3} \pi\right)}+e_{\mathrm{C}_{p}}(t) e^{j\left(\alpha_{p}-\frac{2}{3} \pi\right)}\right] .
\end{gathered}
$$

The phase currents flowing through phase $A_{1}, B_{1}, C_{1}, \ldots, A_{N}$, $\mathrm{B}_{N}, \mathrm{C}_{N}$, are represented by $i_{\mathrm{A}_{1}}, i_{\mathrm{B}_{1}}, i_{\mathrm{C}_{1}}, \ldots, i_{\mathrm{A}_{N}}, i_{\mathrm{B}_{N}}, i_{\mathrm{C}_{N}}$ respectively. The phase current space vector representative of all the $N$ three-phase systems $\vec{\imath}_{\text {total }}(t)$ can be expressed by (2):

$$
\begin{gathered}
\vec{l}_{\text {total }}(t)=\frac{2}{3 N} \sum_{p=1}^{N}\left[i_{\mathrm{A}_{p}}(t) e^{j \alpha_{p}}\right. \\
\left.+i_{\mathrm{B}_{p}}(t) e^{j\left(\alpha_{p}+\frac{2}{3} \pi\right)}+i_{\mathrm{C}_{p}}(t) e^{j\left(\alpha_{p}-\frac{2}{3} \pi\right)}\right] .
\end{gathered}
$$

It results, from (1) and (2), that the instantaneous torque generated by the $N$ three-phase systems can be written as (3): 


$$
T_{\text {total }}(t)=\frac{3 N}{2 \omega_{m}}\left[\vec{l}_{\text {total }}(t) \cdot \vec{e}_{\text {total }}(t)\right] .
$$

Owing to the symmetrical distribution of the different threephase windings under the different pole pairs, typical of a sectored machine, the space phase shift angles $\alpha_{p}$ is 0 .

\section{PWM RELATED TORQUE RIPPLE}

For double-edge naturally sampled pulse width modulation, the harmonic components of the PWM voltage waveform of each converter leg, and the resulting phase voltage, can be evaluated by using the double Flourier integration [31]. The voltage difference between the terminals $\mathrm{a}_{1}, \mathrm{~b}_{1}, \mathrm{c}_{1}, \ldots, \mathrm{a}_{N}, \mathrm{~b}_{N}$, $\mathrm{c}_{N}$ and the middle point of the DC link (z in Fig. 1) is referred to as $u_{k_{p} z}$. Its time-varying expression $u_{k_{p} z}(t)$ can be represented by (4):

$$
\begin{gathered}
u_{k_{p} \mathrm{z}}(t)=\frac{V_{\mathrm{dc}}}{2} M \cos \left[y(t)-\alpha_{p}\right] \\
+\sum_{m=1}^{\infty} \sum_{n=-\infty}^{\infty} A_{m n} \cos \left\{m x_{p}(t)+n\left[y(t)-\alpha_{p}\right]\right\},
\end{gathered}
$$
with:

$$
\begin{gathered}
A_{m n}=\frac{2 V_{\mathrm{dc}}}{m \pi} J_{n}\left(m \frac{\pi}{2} M\right) \sin \left[(m+n) \frac{\pi}{2}\right], \\
x_{p}(t)=\omega_{\mathrm{c}} t+\theta_{\mathrm{c}, p}, \\
y(t)=\omega_{\mathrm{o}} t+\theta_{\mathrm{o}},
\end{gathered}
$$

where $k \in\{a, b, c\}$ and $p \in\{1, \ldots, N\}$.

The voltage difference between $o_{p}$ and $\mathrm{z}$, is referred to as the common mode voltage $u_{\mathrm{o}_{p} \mathrm{z}}$. Since each three-phase system is star connected, according to Kirchhoff's law, the common mode voltage will not generate any zero sequence current. Therefore, the common mode voltage will not lead to torque ripple, and its effects are not considered in this paper. The phase voltage is the voltage drop between the terminals $\mathrm{a}_{1}, \mathrm{~b}_{1}, \mathrm{c}_{1}, \ldots, \mathrm{a}_{N}, \mathrm{~b}_{N}, \mathrm{c}_{N}$ and the terminals $o_{1}, \ldots, o_{N}$, and are named as $u_{\mathrm{A}_{1}}, u_{\mathrm{B}_{1}}, u_{\mathrm{C}_{1}}$, $\ldots, u_{\mathrm{A}_{N}}, u_{\mathrm{B}_{N}}, u_{\mathrm{C}_{N}}$ respectively. Removing all the common mode voltage components from the phase leg voltages $u_{k_{p} \mathrm{z}}(t)$, the total phase voltage space vector of all the $N$ three-phase systems $\vec{u}_{\text {total }}(t)$ can be defined as:

$$
\begin{gathered}
\sum_{p=1}^{N} \sum_{m=1}^{\infty} \sum_{n=-\infty}^{\infty}\left\{\begin{array}{cc}
e^{j\left[m x_{p}(t)+n\left(y(t)-\alpha_{p}\right)+\alpha_{p}\right]}, & n=3 l+1 \\
0, & n=3 l \\
e^{\left.-j\left[m x_{p}(t)+n\left(y(t)-\alpha_{p}\right)-\alpha_{p}\right)\right]}, & n=3 l-1
\end{array}\right.
\end{gathered}
$$

where $l$ is an integer number. The voltage space vector $\vec{u}_{\text {total }}(t)$ contains the fundamental component $\frac{V_{\mathrm{dc}}}{2} M e^{j y(t)}$ and the harmonic components which are caused by the PWM. The harmonic components include both positive sequence components:

$$
\frac{1}{N} A_{m n} \sum_{p=1}^{N} \sum_{m=1}^{\infty} \sum_{n=-\infty}^{\infty} e^{j\left[m x_{p}(t)+n\left(y(t)-\alpha_{p}\right)+\alpha_{p}\right]},
$$

and negative sequence components:

$$
\frac{1}{N} A_{m n} \sum_{p=1}^{N} \sum_{m=1}^{\infty} \sum_{n=-\infty}^{\infty} e^{\left.-j\left[m x_{p}(t)+n\left(y(t)-\alpha_{p}\right)-\alpha_{p}\right)\right]} .
$$

The main torque ripple caused by the PWM is due to the interaction of the high order winding field harmonics with the fundamental component of the permanent magnet field. The torque ripple caused by the interaction of the high order harmonics $\left(5^{\text {th }}, 7^{\text {th }}, 11^{\text {th }}, 13^{\text {th }} \ldots\right)$ is neglected in this analysis. Thus, only the fundamental component of the total back-EMF space vector $\vec{e}_{\text {total,f }}(t)$ is considered while modelling the total phase current space vector $\vec{\imath}_{\text {total }}(t)$, which can be represented by (9):

$$
\begin{gathered}
\vec{\imath}_{\text {total }}(t)=I_{\mathrm{f}} e^{j y^{\prime}(t)}+\frac{1}{N} \frac{A_{m n}}{Z\left(\omega_{m n}\right)} \\
\sum_{p=1}^{N} \sum_{m=1}^{\infty} \sum_{n=-\infty}^{\infty}\left\{\begin{array}{cc}
e^{j\left[m x_{p}(t)+n\left(y(t)-\alpha_{p}\right)+\alpha_{p}\right]}, & n=3 l+1 \\
0, & n=3 l \\
e^{\left.-j\left[m x_{p}(t)+n\left(y(t)-\alpha_{p}\right)-\alpha_{p}\right)\right]}, & n=3 l-1
\end{array}\right.
\end{gathered}
$$

with:

$$
\begin{gathered}
I_{\mathrm{f}} e^{j y^{\prime}(t)=} \frac{1}{Z\left(\omega_{o}\right)}\left[\frac{V_{\mathrm{dc}}}{2} M e^{j y(t)}-\vec{e}_{\mathrm{total}, \mathrm{f}}(t)\right], \\
y^{\prime}(t)=\omega_{\mathrm{o}} t+\theta_{\mathrm{o}}^{\prime}, \\
\omega_{m n}=n \omega_{\mathrm{o}}+m \omega_{\mathrm{c}},
\end{gathered}
$$

Under the assumption of considering for only the fundamental component of the total back-EMF space vector $\vec{e}_{\text {total,f }}(t)$, the instantaneous torque can be rewritten as:

$$
T_{\text {total,PWM }}(t)=\frac{3 N}{2 \omega_{m}}\left[\vec{l}_{\text {total }}(t) \cdot \vec{e}_{\text {total,f }}(t)\right]
$$

It results from (13) that the average torque is produced by controlling the fundamental component $I_{\mathrm{f}}$ of the total current space vector $\vec{l}_{\text {total }}(t)$, whereas the main torque ripple caused by the PWM is generated by the harmonic components in the total current space vector $\vec{l}_{\text {total }}(t)$. Therefore, the minimization of the harmonic components of the total current space vector $\vec{\imath}_{\text {total }}(t)$ corresponds to the minimization of the related torque ripple. As it is expressed in (9), there are $N$ degrees of freedom to change the carrier phase angle $\theta_{c, p}$ of each sub three-phase system. Thus, different optimized carrier phase angles $\theta_{c, p}$ can be found for multi three-phase drives with different values of three-phase systems $N$ and related phase shift angles $\alpha_{p}$.

\section{Case Study on a TRIPle Three-Phase Sectored PMSM}

As a case study, an 18 slots and 6 poles triple three-phase PMSM is shown in Fig. 2. The machine has three sectors, sector 1 , sector 2 and sector 3 respectively. Each sector has three phases (phase A, phase B, phase C) with an independent floating neutral point. Therefore, the three-phase back-EMFs generated

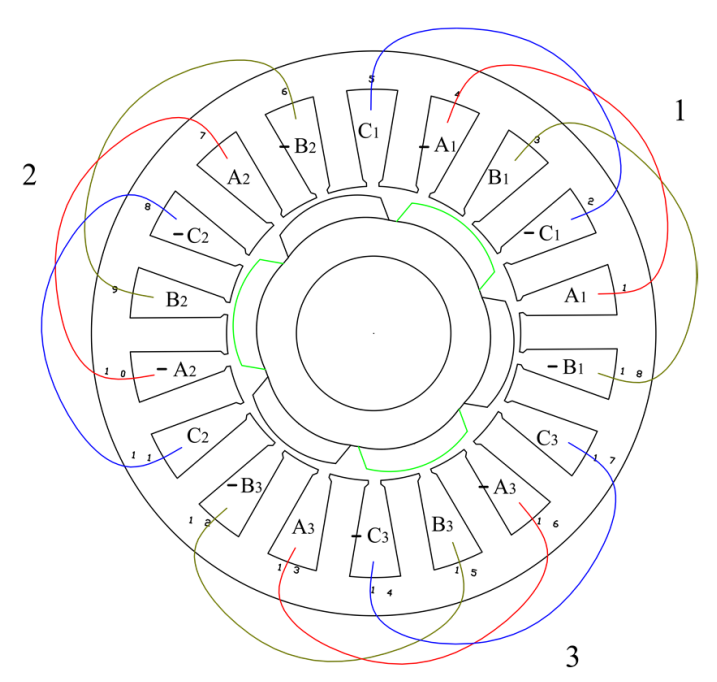

Fig. 2. Cross section of the 18 slots -6 poles 3 sectored PM machine. 
in each sector are supposed to have no electrical degree phase shift with respect to other sectors.

For the mathematical model of the total current space vector $\vec{i}_{\text {total }}(t)$ shown in (9), the number of three-phase systems is 3 $(N=3)$ and the equivalent space phase shift angle is 0 for all of the three sectors $\left(\alpha_{p}=0, p \in\{1,2,3\}\right)$. By analyzing the effect of the carrier phase angle of the $p^{\text {th }}$ three-phase system $\theta_{c, p}$ $\left(x_{p}(t)=\omega_{\mathrm{c}} t+\theta_{\mathrm{c}, p}\right)$ in the voltage and current total space vector equations (8)-(9), it can be found that when the carrier phase shift angles are $\theta_{\mathrm{c}, 1}=0, \theta_{\mathrm{c}, 2}=\frac{2 \pi}{3}$ and $\theta_{\mathrm{c}, 3}=\frac{4 \pi}{3}$ for sector 1 , sector 2 and sector 3 respectively, all of the harmonic components of the current space vector are cancelled out except the groups of harmonics around the frequency of $3 m f_{c}(m \in$ $\{1,2, \ldots, \infty\})$. As it is shown in (5) and (9), the amplitude of each PWM harmonic component changes under different moduation index $(M)$. The modulation index is one of the main factor affecting the amplitudes of the harmonics. According to (13), the corresponding FFT spectrum of the normalized torque without and with applying the proposed carrier phase shift angles under different modulation index $(M)$ is shown in Fig. 3.

The cross section of the considered machine is shown in Fig. 2. The self-inductance of each stator phase $A_{1}, B_{1}, C_{1}, A_{2}, B_{2}$, $\mathrm{C}_{2}, \mathrm{~A}_{3}, \mathrm{~B}_{3}, \mathrm{C}_{3}$ are represented by $L_{\mathrm{A}_{1}}, L_{\mathrm{B}_{1}}, L_{\mathrm{C}_{1}}, L_{\mathrm{A}_{2}}, L_{\mathrm{B}_{2}}$, $L_{\mathrm{C}_{2}}, L_{\mathrm{A}_{3}}, L_{\mathrm{B}_{3}}, L_{\mathrm{C}_{3}}$, respectively. The mutual inductance between the phases $A_{1}, B_{1}, C_{1}, A_{2}, B_{2}, C_{2}, A_{3}, B_{3}, C_{3}$ are represented by $M_{\mathrm{A}_{1} \mathrm{~B}_{1}}, M_{\mathrm{A}_{1} \mathrm{C}_{1}}, \ldots, M_{\mathrm{C}_{3} \mathrm{~A}_{3}}, M_{\mathrm{C}_{3} \mathrm{~B}_{3}}$ respectively. Due to the symmetrical design of the winding configuration in Fig. 2, the matrix inductance table $\boldsymbol{L}$ of the machine can be represented by:

$\boldsymbol{L}=$

$\left[\begin{array}{ccccccccc}L & -M_{1} & -M_{1} & -M_{3} & M_{3} & M_{3} & -M_{3} & M_{3} & M_{3} \\ -M_{1} & L & M_{2} & M_{3} & -M_{3} & -M_{3} & M_{3} & -M_{3} & -M_{3} \\ -M_{1} & M_{2} & L & M_{3} & -M_{3} & -M_{3} & M_{3} & -M_{3} & -M_{3} \\ -M_{3} & M_{3} & M_{3} & L & -M_{1} & -M_{1} & -M_{3} & M_{3} & M_{3} \\ M_{3} & -M_{3} & -M_{3} & -M_{1} & L & M_{2} & M_{3} & -M_{3} & -M_{3} \\ M_{3} & -M_{3} & -M_{3} & -M_{1} & M_{2} & L & M_{3} & -M_{3} & -M_{3} \\ -M_{3} & M_{3} & M_{3} & -M_{3} & M_{3} & M_{3} & L & -M_{1} & -M_{1} \\ M_{3} & -M_{3} & -M_{3} & M_{3} & -M_{3} & -M_{3} & -M_{1} & L & M_{2} \\ M_{3} & -M_{3} & -M_{3} & M_{3} & -M_{3} & -M_{3} & -M_{1} & M_{2} & L\end{array}\right]$

where: $L=L_{k_{p}}, k \in\{\mathrm{A}, \mathrm{B}, \mathrm{C}\}, \quad p \in\{1,2,3\} ; M_{\mathrm{A}_{p} k_{p}^{1}}=$ $M_{k_{p}^{1} \mathrm{~A}_{p}}=M_{1}, k^{1} \in\{\mathrm{B}, \mathrm{C}\} ; M_{\mathrm{B}_{p} \mathrm{C}_{p}}=M_{\mathrm{C}_{p} \mathrm{~B}_{p}}=M_{2} ; M_{k_{p} k_{p^{\prime}}^{\prime}}=$ $M_{3}, k, k^{\prime} \in\{\mathrm{A}, \mathrm{B}, \mathrm{C}\}, p, p^{\prime} \in\{1,2,3\}, p \neq p^{\prime}$.

The PWM related phase voltage harmonics and phase current harmonics of the $p^{\text {th }}$ three-phase system can be represented by $u_{k_{p}, \mathrm{~h}}$ and $i_{k_{p}, \mathrm{~h}}(p \in\{1,2,3\})$ respectively. Since the three phases in each sector are star-connected, the sum of three-phase currents is zero in any sector, leading to the following constraint:

$$
i_{\mathrm{A}_{p} \mathrm{~h}}+i_{\mathrm{B}_{p}, \mathrm{~h}}+i_{\mathrm{C}_{p, \mathrm{~h}}}=0,
$$

According to the electric principle, the corresponding $p^{\text {th }}$ phase voltage harmonic $u_{\mathrm{A}_{p}, \mathrm{~h}}, u_{\mathrm{B}_{p}, \mathrm{~h}}, u_{\mathrm{C}_{p}, \mathrm{~h}}$ can be represented by (15) (16) and (17) respectively:

$$
\begin{gathered}
u_{\mathrm{A}_{p}, \mathrm{~h}}=R i_{\mathrm{A}_{p}, \mathrm{~h}}+\left(L+M_{1}\right) \frac{\mathrm{d}}{\mathrm{d} t} i_{\mathrm{A}_{p}, \mathrm{~h}} \\
-\left(2 M_{3}\right) \frac{\mathrm{d}}{\mathrm{d} t}\left(i_{\mathrm{A}_{p^{\prime}, \mathrm{h}}}+i_{\mathrm{A}_{p^{\prime \prime}}, \mathrm{h}}\right),
\end{gathered}
$$

$$
\begin{aligned}
& u_{\mathrm{B}_{p}, \mathrm{~h}}=R i_{\mathrm{B}_{p}, \mathrm{~h}}+\left(L+M_{1}\right) \frac{\mathrm{d}}{\mathrm{d} t} i_{\mathrm{B}_{p}, \mathrm{~h}}+\left(M_{1}+M_{2}\right) \frac{\mathrm{d}}{\mathrm{d} t} i_{\mathrm{C}_{p}, \mathrm{~h}} \\
& -\left(2 M_{3}\right) \frac{\mathrm{d}}{\mathrm{d} t}\left(i_{\mathrm{B}_{p^{\prime}, \mathrm{h}}}+i_{\mathrm{B}_{p^{\prime \prime}, \mathrm{h}}}\right)-\left(2 M_{3}\right) \frac{\mathrm{d}}{\mathrm{d} t}\left(i_{\mathrm{C}_{p^{\prime}}, \mathrm{h}}+i_{\mathrm{C}_{p^{\prime \prime}}, \mathrm{h}}\right),(16) \\
& u_{\mathrm{C}_{p}, \mathrm{~h}}=R i_{\mathrm{C}_{p}, \mathrm{~h}}+\left(L+M_{1}\right) \frac{\mathrm{d}}{\mathrm{d} t} i_{\mathrm{C}_{p, \mathrm{~h}}}+\left(M_{1}+M_{2}\right) \frac{\mathrm{d}}{\mathrm{d} t} i_{\mathrm{B}_{p}, \mathrm{~h}} \\
& -\left(2 M_{3}\right) \frac{\mathrm{d}}{\mathrm{d} t}\left(i_{\mathrm{C}_{p^{\prime}, \mathrm{h}}}+i_{\mathrm{C}_{p^{\prime \prime}, \mathrm{h}}}\right)-\left(2 M_{3}\right) \frac{\mathrm{d}}{\mathrm{d} t}\left(i_{\mathrm{B}_{p^{\prime}, \mathrm{h}}}+i_{\mathrm{B}_{p^{\prime \prime}}, \mathrm{h}}\right) .(17)
\end{aligned}
$$

where $p, p^{\prime}, p^{\prime \prime} \in\{1,2,3\}, p \neq p^{\prime} \neq p^{\prime \prime}$. The fundamental components of phase currents and phase voltages are not defined by (15)-(17) as the back-EMFs are not included. As it is mentioned above, for this case study, the electrical phase shift among the various three-phase systems is zero. $\left(\alpha_{p}=0, p \in\right.$ $\{1,2,3\})$. Therefore, without CPS-PWM method $\left(\theta_{c, 1}=\theta_{c, 2}=\right.$ $\left.\theta_{c, 3}=0\right)$, the phase current harmonics of each sector are the same $\left(i_{k_{p}, \mathrm{~h}}=i_{k_{p^{\prime}, \mathrm{h}}}=i_{k_{p^{\prime \prime}, \mathrm{h}}}, k \in\{\mathrm{A}, \mathrm{B}, \mathrm{C}\}\right)$. By properly manipulating (15), (16) and (17), the corresponding $p^{\text {th }}$ phase voltage harmonic $u_{\mathrm{A}_{p}, \mathrm{~h}}, u_{\mathrm{B}_{p}, \mathrm{~h}}, u_{\mathrm{C}_{p}, \mathrm{~h}}$ without applying CPSPWM can be respectively rewritten as:

$$
\begin{gathered}
u_{\mathrm{A}_{p}, \mathrm{~h}}=R i_{\mathrm{A}_{p}, \mathrm{~h}}+\left(L+M_{1}-4 M_{3}\right) \frac{\mathrm{d}}{\mathrm{d} t} i_{\mathrm{A}_{p}, \mathrm{~h}}, \\
u_{\mathrm{B}_{p}, \mathrm{~h}}=R i_{\mathrm{B}_{p}, \mathrm{~h}}+\left(L+M_{1}-4 M_{3}\right) \frac{\mathrm{d}}{\mathrm{d} t} i_{\mathrm{B}_{p}, \mathrm{~h}}
\end{gathered}
$$
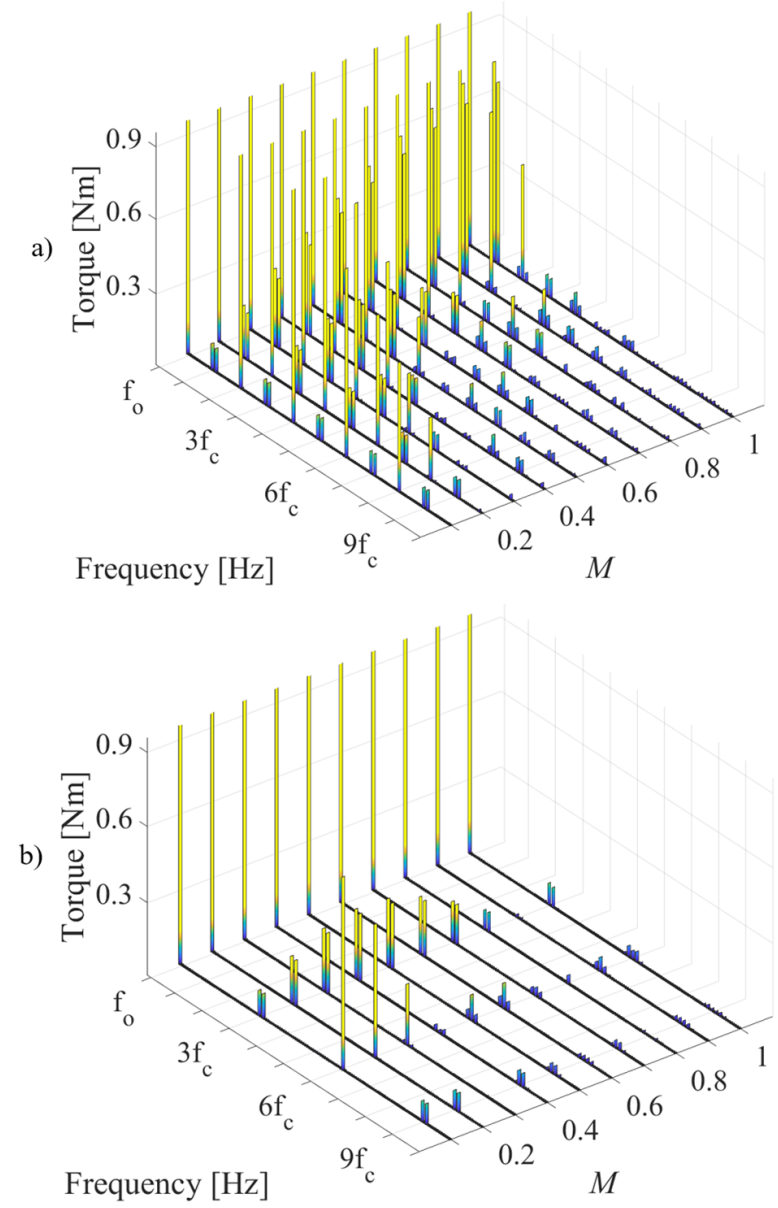

Fig. 3. FFT spectrum of the normalized torque a) without applying carrier phase shift method $b$ ) with applying the proposed carrier phase shift method. 


$$
\begin{gathered}
+\left(M_{1}+M_{2}-4 M_{3}\right) \frac{\mathrm{d}}{\mathrm{d} t} i_{\mathrm{C}_{p}, \mathrm{~h}}, \\
u_{\mathrm{C}_{p}, \mathrm{~h}}=R i_{\mathrm{C}_{p}, \mathrm{~h}}+\left(L+M_{1}-4 M_{3}\right) \frac{\mathrm{d}}{\mathrm{d} t} i_{\mathrm{C}_{p}, \mathrm{~h}} \\
+\left(M_{1}+M_{2}-4 M_{3}\right) \frac{\mathrm{d}}{\mathrm{d} t} i_{\mathrm{B}_{p}, \mathrm{~h}} .
\end{gathered}
$$

Whereas, by applying the proposed CPS-PWM method $\left(\theta_{\mathrm{c}, 1}=\right.$ $\left.0, \theta_{c, 2}=\frac{2 \pi}{3}, \theta_{c, 3}=\frac{4 \pi}{3}\right)$, there are two conditions of phase current harmonics according to (9). First, for the harmonic components of the total current space vector which cannot be cancelled out by the CPS-PWM method (around the frequency of $\left.3 z f_{c}, z \in\{1,2, \ldots, \infty\}\right)$, the relevant phase current harmonics of each sector are the same $\left(i_{k_{1}, \mathrm{~h}}=i_{k_{2}, \mathrm{~h}}=i_{k_{3}, \mathrm{~h}}, k \in\{\mathrm{A}, \mathrm{B}, \mathrm{C}\}\right)$. Therefore, the corresponding $p^{\text {th }}$ phase voltage harmonics $u_{\mathrm{A}_{p}, \mathrm{~h}}, u_{\mathrm{B}_{p}, \mathrm{~h}}, u_{\mathrm{C}_{p}, \mathrm{~h}}$ with applying CPS-PWM can be represented by (18), (19) and (20) respectively. Secondly, for the harmonic components of the total current space vector which can be cancelled out by the CPS-PWM method (around the frequency of $z f_{\mathrm{c}}$ and $2 z f_{\mathrm{c}}, \mathrm{z} \in\{1,2, \ldots, \infty\}$ ), the sum of phase current

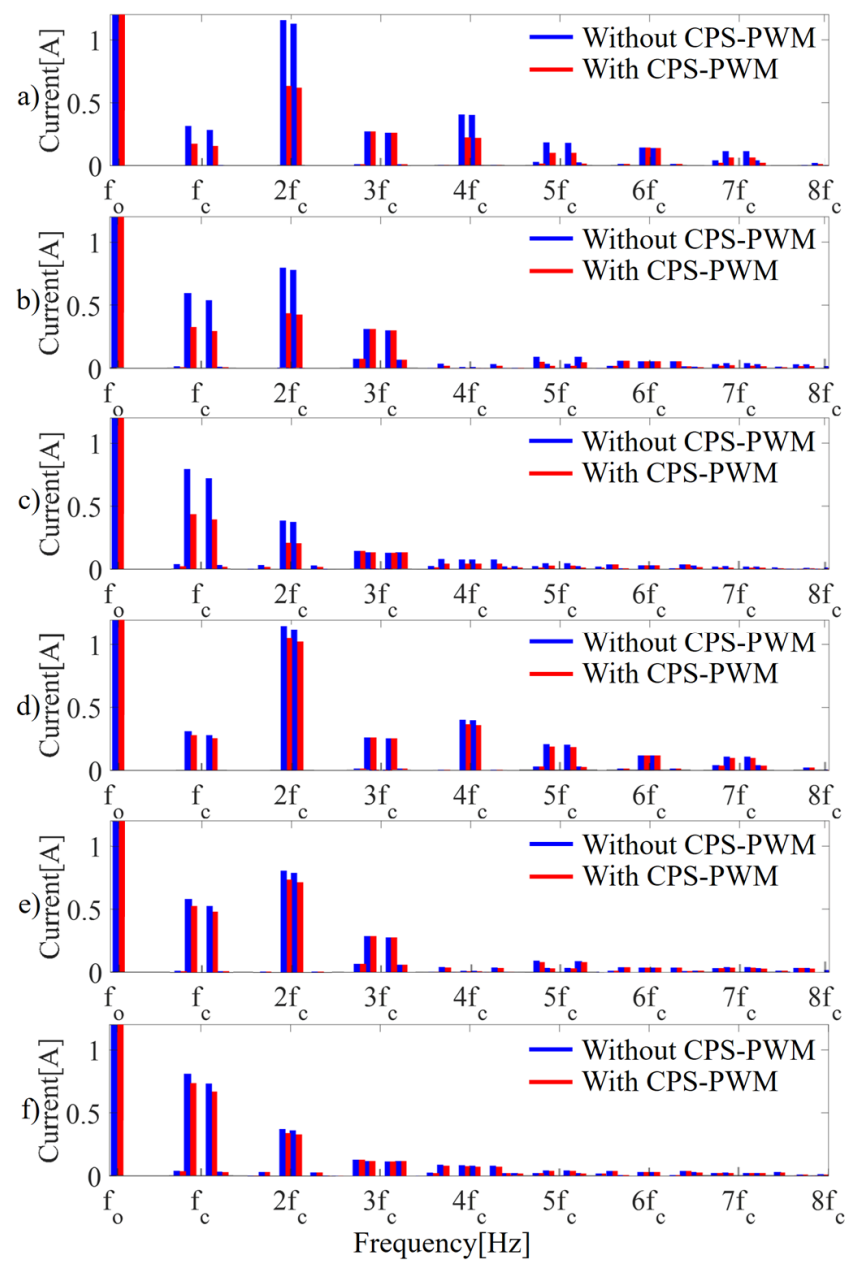

Fig. 4. Numerical result of phase current FFT spectrum without and with CPS-PWM a) current phase A with $M=0.3 \mathrm{~b}$ ) current phase A with $M=0.6 \mathrm{c}$ ) current phase A with $M=0.9 \mathrm{~d}$ ) current phase $\mathrm{B} \& \mathrm{C}$ with $M=0.3 \mathrm{e}$ ) current phase $\mathrm{B} \& \mathrm{C}$ with $M=0.6 \mathrm{f}$ ) current phase $\mathrm{B} \& \mathrm{C}$ with $M=0.9$. harmonics from different sectors is equal to 0 , which can be represented by (21):

$$
i_{k, \mathrm{~h}}=\sum_{p=1}^{N} i_{k_{p}, \mathrm{~h}}=i_{k_{1}, \mathrm{~h}}+i_{k_{2}, \mathrm{~h}}+i_{k_{3}, \mathrm{~h}}=0,
$$

where $k \in\{\mathrm{A}, \mathrm{B}, \mathrm{C}\}$. It results that the corresponding $p^{\text {th }}$ phase voltage harmonic $u_{\mathrm{A}_{p}, \mathrm{~h}}, u_{\mathrm{B}_{p}, \mathrm{~h}}, u_{\mathrm{C}_{p}, \mathrm{~h}}$ with applying CPS-PWM can be represented by (22) (23) and (24) respectively:

$$
\begin{gathered}
u_{\mathrm{A}_{p}, \mathrm{~h}}=R i_{\mathrm{A}_{p}, \mathrm{~h}}+\left(L+M_{1}+2 M_{3}\right) \frac{\mathrm{d}}{\mathrm{d} t} i_{\mathrm{A}_{p}, \mathrm{~h}}, \\
u_{\mathrm{B}_{p}, \mathrm{~h}}=R i_{\mathrm{B}_{p}, \mathrm{~h}}+\left(L+M_{1}+2 M_{3}\right) \frac{\mathrm{d}}{\mathrm{d} t} i_{\mathrm{B}_{p}, \mathrm{~h}} \\
+\left(M_{1}+M_{2}+2 M_{3}\right) \frac{\mathrm{d}}{\mathrm{d} t} i_{\mathrm{C}_{p}, \mathrm{~h}}, \\
u_{\mathrm{C}_{p}, \mathrm{~h}}=R i_{\mathrm{C}_{p}, \mathrm{~h}}+\left(L+M_{1}+2 M_{3}\right) \frac{\mathrm{d}}{\mathrm{d} t} i_{\mathrm{C}_{p}, \mathrm{~h}} \\
+\left(M_{1}+M_{2}+2 M_{3}\right) \frac{\mathrm{d}}{\mathrm{d} t} i_{\mathrm{B}_{p}, \mathrm{~h}} .
\end{gathered}
$$

For phase $\mathrm{A}$ in each sector, the effective inductance $\left(L+M_{1}-\right.$ $\left.4 M_{3}\right)$ in $(18)$ is smaller than the effective inductance $\left(L+M_{1}+\right.$ $2 M_{3}$ ) in (22). For phase $\mathrm{B}$ and $\mathrm{C}$ in each sector, the effective self-inductance $\left(L+M_{1}-4 M_{3}\right)$ in (19) and (20) is smaller than the effective self-inductance $\left(L+M_{1}+2 M_{3}\right)$ in (23) and (24); the effective mutual inductance between phase $\mathrm{B}$ and $\mathrm{C}\left(M_{1}+\right.$ $\left.M_{2}-4 M_{3}\right)$ in (19) and (20) is smaller than the effective mutual inductance $\left(M_{1}+M_{2}+2 M_{3}\right)$ in (23) and (24). Overall, for the considered sectored machine, the effective inductance without applying CPS-PWM method is smaller than the effective inductance with applying CPS-PWM. The amplitudes of phase voltage harmonics with and without CPS-PWM are the same [31]. Therefore, the amplitudes of phase current harmonics with applying CPS-PWM method are smaller than the ones obtained without the CPS-PWM method. The numerical results obtained in PLECS of the normalized phase current FFT spectrum with and without CPS-PWM under different modulation index ( $M=$ $0.3, M=0.6$ and $M=0.9$ ) is shown in Fig. 4 .

It results that applying the CPS-PWM method to the triple three-phase sectored PMSM machine brings two major advantages to the machine. First, the torque ripple of machine is reduced, hence the noise and vibration of the machine is effectively reduced. Secondly, the phase current harmonic is reduced as well, hence less copper loss of the machine is expected.

\section{ANAlytical, Numerical and FEA Results}

Analytical, numerical and FEA simulations have been carried out in order to evaluate and validate the advantages of the proposed control of the carrier phase angles. Analytical results are obtained using the time-varying equations (13) (18) and (22) in Matlab. The numerical results are obtained by using variablestep simulations in PLECS. The operating condition concerning the numerical results is no load condition. There is no external load on the machine and the machine operating power is to overcome the mechanical (friction) power loss and the electromagnetic power loss of the machine itself. FEA results are finally realized by Magnet with the triple three-phase machine model (Fig. 2) excited by the currents resulting from the PLECS simulation. The numerical and FEA results are used to validate the analytical model described by (13) (18) and (22), and quantify the phase current and torque ripple with and 
TABLE I

CONVERTER AND MACHINE PARAMETERS

\begin{tabular}{ll}
\hline \hline Parameter & Value \\
\hline DC voltage $\left(\mathrm{V}_{\mathrm{dc}}\right)$ & $60[\mathrm{~V}]$ \\
Switching frequency $\left(f_{\mathrm{c}}\right)$ & $2[\mathrm{kHz}]$ \\
Modulating frequency $\left(f_{\mathrm{o}}\right)$ & $50[\mathrm{~Hz}]$ \\
Pole pair number & 3 \\
Power rating of the machine & $1.5[\mathrm{kw}]$ \\
Rated torque of the machine & $5[\mathrm{Nm}]$ \\
Rated current of the machine & $11.5[\mathrm{Apk}]$ \\
Rated voltage of the machine & $28.5[\mathrm{Vpk}]$ \\
Phase resistance $(R)$ & $0.08[\Omega]$ \\
Stator inductance matrix $(L)$ & $L=0.31 ; M_{1}=0.087 ; M_{2}=0.03 ;$ \\
& $M_{3}=0.029[\mathrm{mH}]$ \\
Mechanical speed $\left(\omega_{m}\right)$ & $104.72[\mathrm{rad} / \mathrm{s}](1000 \mathrm{rpm})$ \\
Back-EMF coefficient $\left(K_{E}\right)$ & $0.085(\mathrm{phase}$ peak back-EMF \\
& is $8.9 \mathrm{~V}$ at $50 \mathrm{~Hz})$ \\
\hline \hline
\end{tabular}

without CPS-PWM. The main converter and machine parameters are shown in Table I.

Fig. 5 shows the block diagram for the control of the ninephase machine fed by its three independent PWM converters. The CPS-PWM method is applied to the three three-phase systems with carrier phase shift angles $\theta_{\mathrm{c}, 1}, \theta_{\mathrm{c}, 2}$, and $\theta_{\mathrm{c}, 3}$ respectively. The machine in the PLECS simulations (numerical results) is controlled in speed, by a simple proportional-integral (PI) controller which provides the same current reference (iq) as input to the internal current PI regulator of each three-phase system.

Fig. 6 shows the comparison of the analytical and numerical models in terms of phase current (phase $A_{1}$ is considered). Fig. $6 \mathrm{a}$ and Fig. $6 \mathrm{c}$ show the analytical and numerical results without applying CPS-PWM method. Fig. 6b and Fig. 6d show the same while applying the CPS-PWM method. Fig. $6 \mathrm{~d}$ shows that there is slightly difference between the analytical and numerical results at the groups of harmonics around $2 \mathrm{kHz}, 4 \mathrm{kHz}, 8 \mathrm{kHz}$, $10 \mathrm{kHz}, 14 \mathrm{kHz}$ and $16 \mathrm{kHz}$. The reason is that the analytical model is based on a simplification of the system considering the equations in electrical degrees for phase $\mathrm{A}_{p}, \mathrm{~B}_{p}$ and $\mathrm{C}_{p}(p \in$ $\{1,2,3\})$ independent from the sector where they are placed. In this machine, due to the sectored stator winding structure, applying CPS-PWM in numerical model will lead to small harmonic phase current difference among phase $\mathrm{A}_{p}, \mathrm{~B}_{p}$ and $\mathrm{C}_{p}$ in each sector, which is shown in Fig. 4.

Fig. 7 shows the numerical current results of phase $A_{1}, A_{2}$ and $A_{3}$ with and without applying CPS-PWM. Fig. $7 \mathrm{~b}$ and Fig. $7 \mathrm{~d}$ are the zoom of the waveform in between the cursor ranges of Fig. 7a and Fig. 7c respectively. Comparing Fig. 7b and Fig. $7 \mathrm{~d}$, the phase current harmonics in different sectors are effectively shifted with applying the CPS-PWM method. Comparing Fig. $7 \mathrm{a}$ and Fig. $7 \mathrm{c}$, the amplitudes of phase current harmonics obtained by applying CPS-PWM are reduced compared with those obtained by not applying the CPS-PWM. The corresponding FFT spectrum of Fig. 7a and Fig. 7c are shown in Fig. 6c and Fig. 6d respectively. For all of the harmonic components except the harmonics around $6 \mathrm{kHz}$ and $12 \mathrm{kHz}$ in Fig. 6c and Fig. 6d (numerical result), their amplitudes in Fig. 6 d are reduced by $45.18 \%$ compared with the ones in Fig. 6c.

Fig. 8 shows the comparison of analytical, numerical and FEA models in terms of the machine electromagnetic torque.

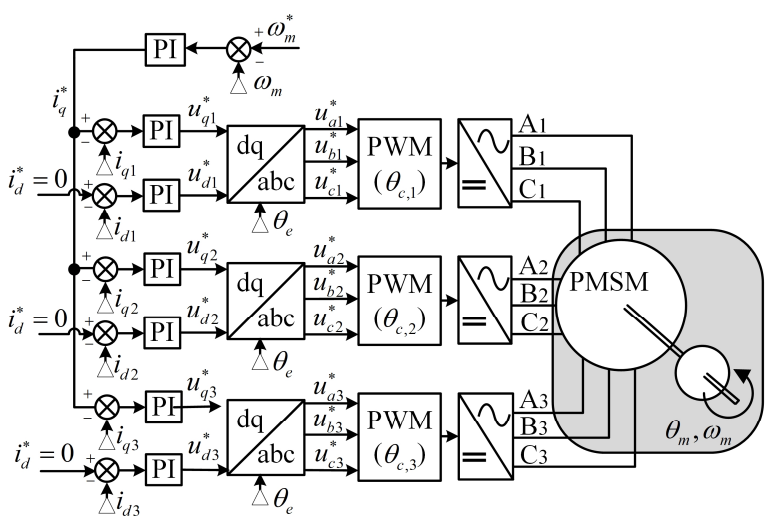

Fig. 5. Block diagram of simulation model.

Fig. 8(a-d) show that the analytical results match with the numerical results for both without and with applying CPS-PWM. Fig. 8(a-b) show that the FEA results match with the analytical and numerical results with a good approximation considering for the analyzed ripple. Fig. 8(c-d) show that there are low order harmonics $\left(6^{\text {th }}\right.$ at $300 \mathrm{~Hz}, 12^{\text {th }}$ at $\left.600 \mathrm{~Hz}\right)$ in FEA results, which are not shown in analytical and numerical results. One reason is that only fundamental component of back-EMF is considered in analytical and numerical models, which has been mentioned in chapter II. In the FEA machine model, the interaction between the fundamental component of winding field and the $5^{\text {th }}, 7^{\text {th }}$, $11^{\text {th }}, 13^{\text {th }} \ldots$ permanent magnet harmonics results in the $6^{\text {th }}$, $12^{\text {th }} \ldots$ harmonics of the torque ripple. The other reason is that the machine model in Magnet is a 6 poles, 18 slots PMSM, and
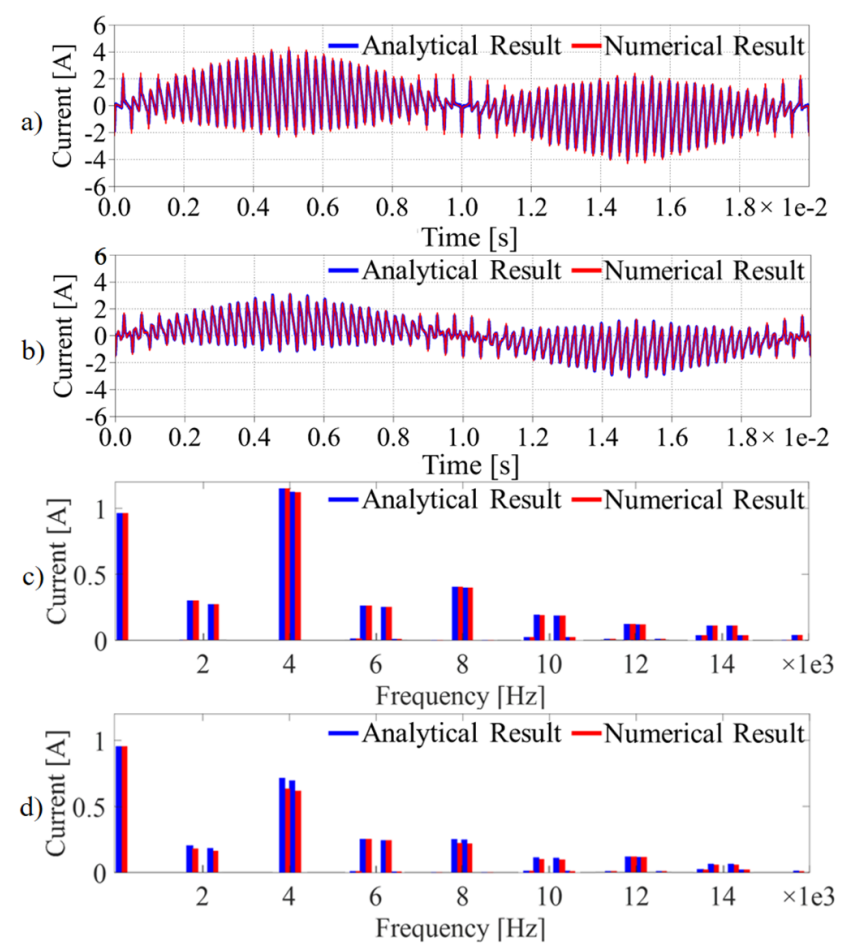

Fig. 6. a) \& b) Analytical and numerical results of phase A1 current waveform a) without CPS-PWM b) with CPS-PWM c) \& d) Analytical and numerical results of phase A1 current FFT spectrum $\mathrm{C}$ ) without CPS-PWM d) with CPS-PWM. 

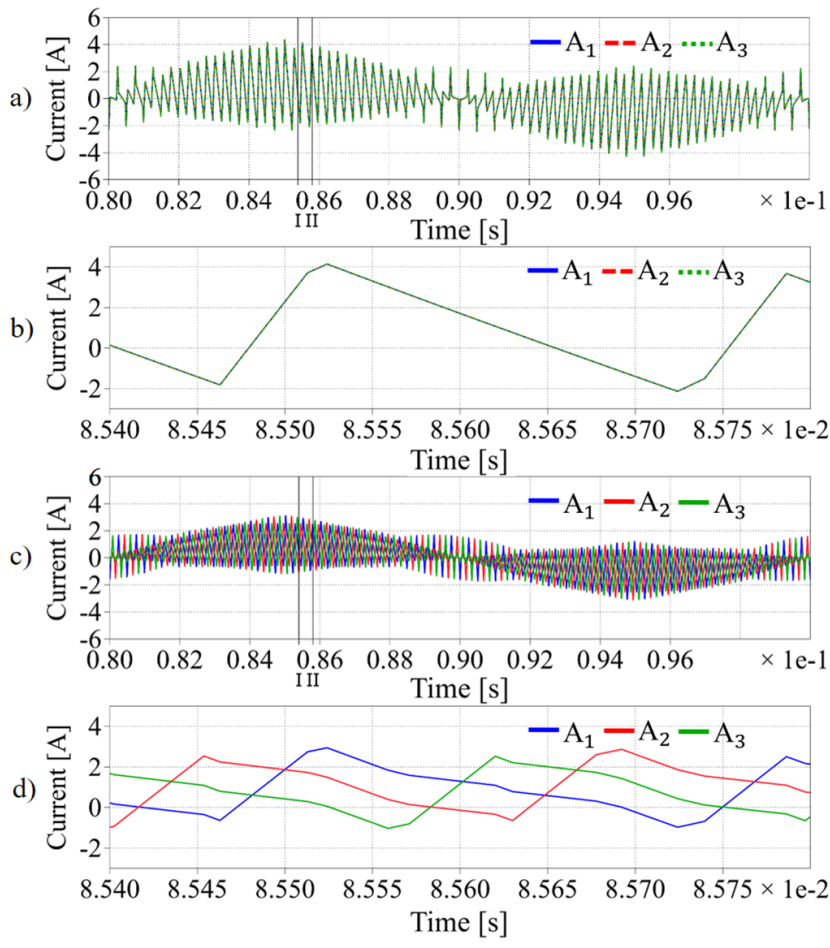

Fig. 7. a) \& b) Numerical results of current waveform of phase A1 A2 \& A3 without CPS-PWM a) One period range of fundamental signal b) Two periods range of carrier signal c) \& d) Numerical results of current waveform of phase A1 A2 \& A3 with CPS-PWM c) One period range of fundamental signal d) Two periods range of carrier signal.

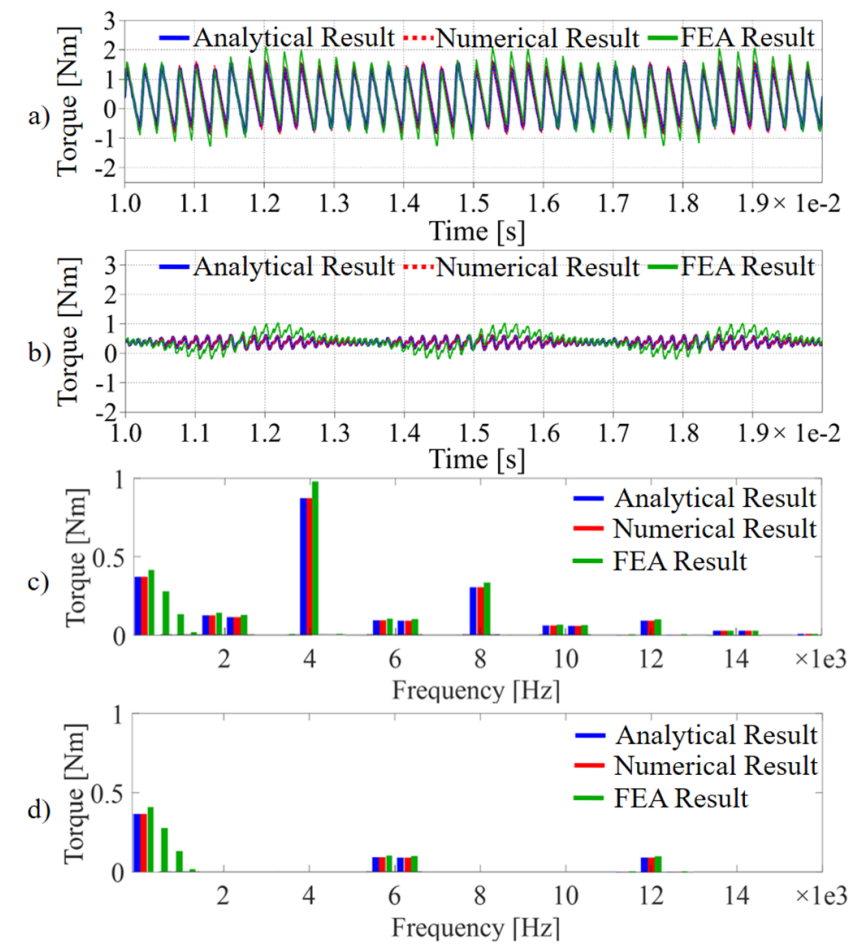

Fig. 8. a) \& b) Analytical, numerical and FEA results of torque waveform a) without CPS-PWM b) with CPS-PWM c) \& d) Analytical, numerical and FEA results of torque FFT spectrum $\mathrm{c}$ ) without CPSPWM d) with CPS-PWM. the interaction between the permanent magnet rotor and stator slots generate $6^{\text {th }}, 12^{\text {th }} \ldots$ harmonics in the torque caused by the cogging effect. In addition, Fig. 8(c-d) show that the FEA result presents slightly higher amplitudes compared with analytical and numerical results, this is due to machine parameter uncertainties in the model, for example the changes of them with working operation due to saturations and non-linear effects.

Comparing the torque waveform with and without CPSPWM, Fig. $8(\mathrm{a}-\mathrm{b})$ show that the peak-to-peak torque are reduced by $79.5 \%, 78.5 \%$ and $63.8 \%$ with applying CPS-PWM in analytical, numerical and FEA results respectively. Fig. 8(cd) show that the harmonic components of the torque FFT spectrum around $2 \mathrm{kHz}, 4 \mathrm{kHz}, 8 \mathrm{kHz}, 10 \mathrm{kHz}, 14 \mathrm{kHz}$ and 16 $\mathrm{kHz}$ obtained by applying CPS-PWM are effectively cancelled out in analytical, numerical and FEA results.

\section{EXPERIMENTAL RESULTS}

In order to validate the analytical model and the simulation results, experimental tests have been carried out by means of the platform shown in Fig. 9. The parameters and the control algorithm used in the experimental platform is the one explained in chapter $\mathrm{V}$. The operating condition concerning the experimental results (same as the numerical result) is no load condition. There is no external load and the machine operating power is to overcome the mechanical (friction) power loss and the electromagnetic power loss of the machine itself. The experimental setup consists of three three-phase inverters with standard IGBT modules, a sectored triple three-phase PMSM with its cross section shown in Fig. 2, and a centralized controller (uCube [32]). Optical fiber is used to communicate between the power module gate drives and the uCube.

Fig. 10 shows the experimental current results of phase $A_{1}$, $A_{2}$ and $A_{3}$ with and without applying CPS-PWM. Fig. 10b and Fig. $10 \mathrm{~d}$ are the zoom of the waveform in between the cursor ranges of Fig. 10a and Fig. 10c respectively. Comparing Fig. $10 \mathrm{~b}$ and Fig. 10d, the phase current harmonics in different sectors are effectively shifted with applying the CPS-PWM method. Comparing Fig. 10a and Fig. 10c, the amplitudes of the phase current harmonics obtained by applying CPS-PWM are

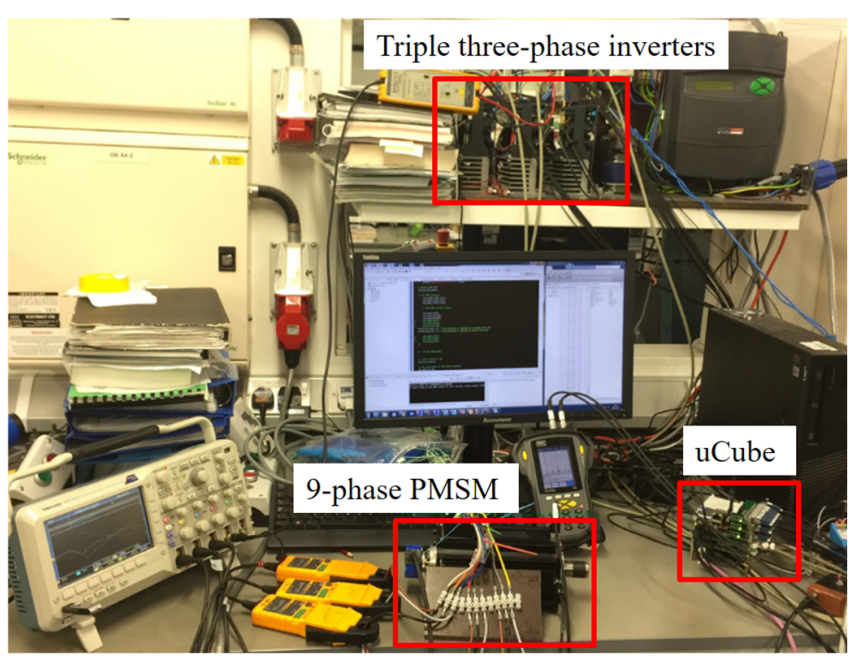

Fig. 9. Triple three-phase machine drive system experimental set-up. 

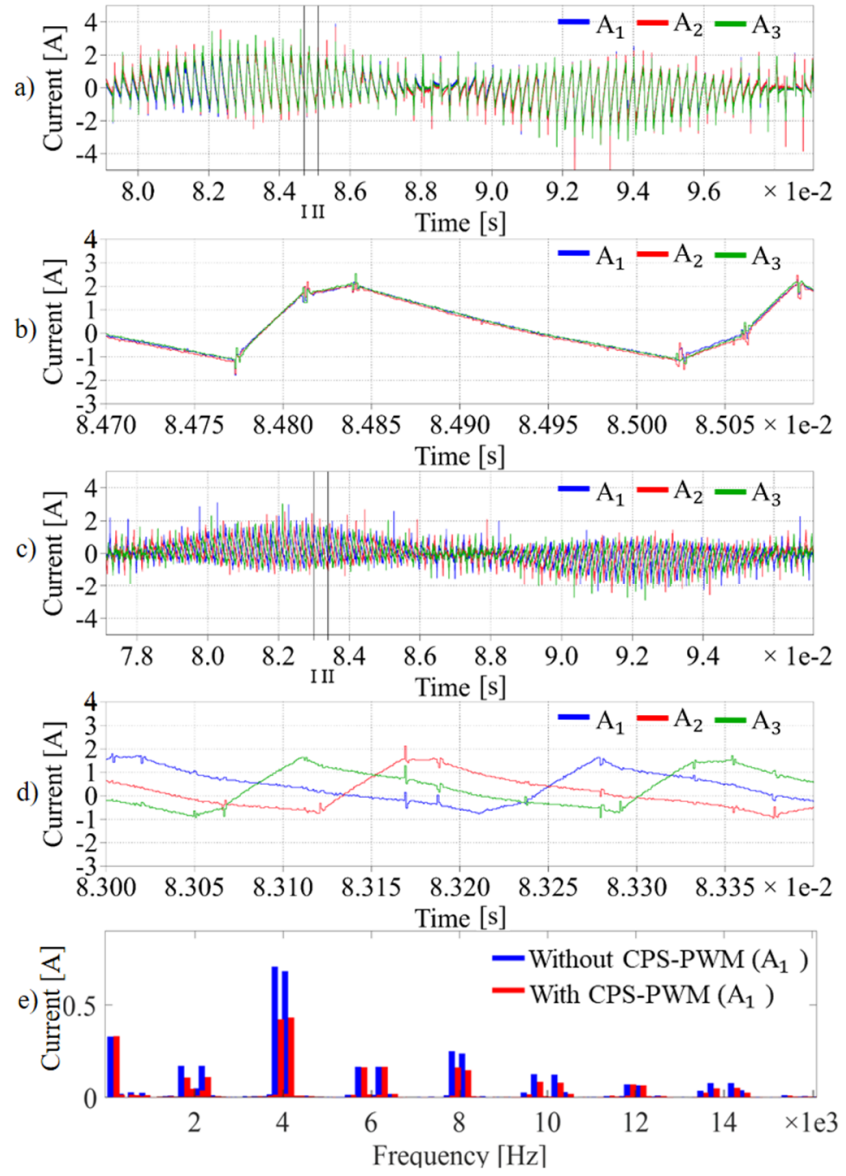

Fig. 10. a) \& b) Experimental result of current waveform of phase A1 A2 \& A3 without CPS-PWM a) One period range of fundamental signal b) Two periods range of carrier signal c) \& d) Experimental results of current waveform of phase A1 A2 \& A3 with CPS-PWM c) One period range of fundamental signal d) Two periods range of carrier signal e) Experimental result of phase A1 current FFT spectrum without and with CPS-PWM.
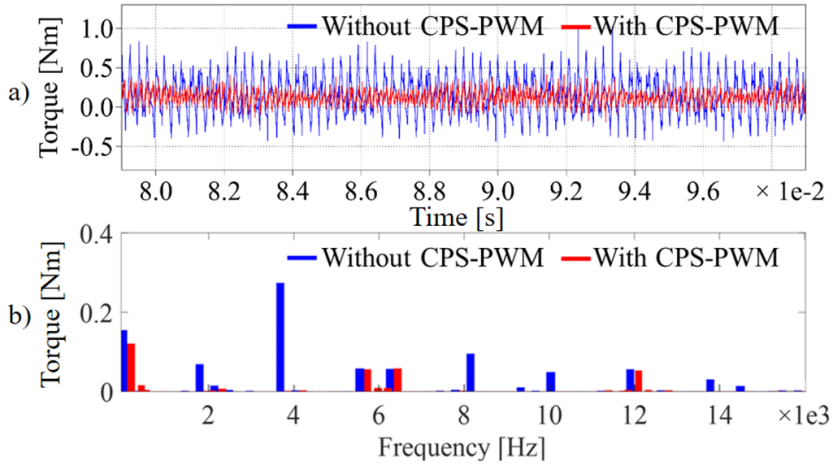

Fig 11. a) Experimental results of equivalent electromagnetic torque waveform with and without CPS-PWM b) FFT spectrum of equivalent electromagnetic torque waveform with and without CPS- PWM.

reduced compared with those obtained by not applying CPSPWM. The corresponding FFT spectrum of Fig. 10a and Fig. $10 \mathrm{c}$ are shown in Fig. 10e, which shows that the amplitudes of harmonic components around $2 \mathrm{kHz}, 4 \mathrm{kHz}, 8 \mathrm{kHz}, 10 \mathrm{kHz}, 14$ $\mathrm{kHz}$ and $16 \mathrm{kHz}$ obtained by applying CPS-PWM are reduced by about $36.1 \% 38.4 \%, 36.1 \%, 34.7 \%, 34.1 \%, \quad 29.5 \%$ respectively compared with those obtained by not applying CPS-PWM. The improvement achieved with CPS-PWM in the experimental results is reduced compared with the improvement in the numerical results, due to the back-EMF distortion, the machine parameter uncertainties, the inverter non-linearity and the dead time effect. Another effect is the switching noise that causes current spikes during the commutations, as visible in Fig. $10 \mathrm{~b}$ and Fig. 10d, that accounts for $4.6 \%$ of torque ripple increase (evaluated by numerically removing the switching noise).

The experimental phase currents are used to calculate the equivalent electromagnetic torque, and only the fundamental component of the back-EMF is considered. The equivalent electromagnetic torque is calculated based on (2) and (13), due to the bandwidth limitation of commercial torque meters. The equivalent electromagnetic torque waveforms and their corresponding FFT spectrum with and without CPS-PWM, are shown in Fig. 11. Comparing the torque waveform with and without CPS-PWM, Fig. 11 a shows that the peak-to-peak torque is reduced by $58.3 \%$ with applying CPS-PWM. The experimental torque ripple reduction of $58.3 \%$ is smaller than the analytical (numerical, FEA) results, but it still represents a major improvement compared to the control without CPSPWM. Fig. 11b shows that the harmonic components of the torque FFT spectrum around $2 \mathrm{kHz}, 4 \mathrm{kHz}, 8 \mathrm{kHz}, 10 \mathrm{kHz}, 14$ $\mathrm{kHz}$ obtained by applying CPS-PWM are effectively cancelled out.

\section{CONCLUSION}

This work proposes a new mathematical modeling approach to multi three-phase drive systems in order to improve the torque performance of multi three-phase machines by applying carrier phase shift among three-phase inverters (CPS-PWM method). Numerical, FEA simulations and experimental tests validate the analytical model shown in Chapter III and IV. The carrier phase shift angles obtained by the developed theory are applied on a case study of a sectored triple three-phase machine. The peak-to-peak values of the torque waveforms obtained by applying CPS-PWM are reduced by $79.5 \%, 78.5 \%, 63.8 \%$ and $58.3 \%$ compared with those obtained by not applying CPSPWM in analytical, numerical, FEA and experimental results respectively. The PWM related harmonic components of the torque FFT spectrum obtained by applying CPS-PWM are effectively cancelled out. In addition, the phase current harmonics in different sectors are effectively shifted with applying the CPS-PWM method. For this case study on the sectored triple three-phase machine, while the CPS-PWM method is applied, the amplitudes of PWM related harmonic components of the phase current FFT spectrum (except the components around $6 \mathrm{kHz}$ and $12 \mathrm{kHz}$ ) are reduced by $45.18 \%$ and about $35 \%$ in numerical and experimental results respectively.

Therefore, applying CPS-PWM method to multi three-phase drives can effectively improve the torque performance of the machine, guaranteeing major benefits in terms of current and torque ripple without additional computational burden. 


\section{REFERENCES}

[1] E. Levi, R. Bojoi, F. Profumo, H. A. Toliyat, and S. Williamson, "Multiphase induction motor drives - a technology status review," IET Electr. Power Appl., vol. 1, no. 4, pp. 485-516, 2007.

[2] J. Dai, S. W. Nam, M. Pande, and G. Esmaeili, "Medium-voltage currentsource converter drives for marine propulsion system using a dualwinding synchronous machine," IEEE Trans. Ind. Appl., vol. 50, no. 6, pp. 3971-3976, 2014.

[3] C. Bassi, A. Tessarolo, R. Menis, and G. Sulligoi, "Analysis of different system design solutions for a high-power ship propulsion synchronous motor drive with multiple PWM cnverters," Int. Conf. Electr. Syst. Aircraft, Railw. Sh. Propulsion, ESARS 2010, pp. 1-6, 2010.

[4] A. Cavagnino, S. Member, A. Tenconi, S. Member, and S. Vaschetto, "Experimental Characterization of a Belt-Driven Multi-Phase Losses and Temperatures Assessments," IEEE Trans. Ind. Appl., vol. 52, no. 2, pp. 1321-1330, 2016.

[5] R. Bojoi, A. Cavagnino, A. Tenconi, and S. Vaschetto, "Control of shaftline-embedded multiphase starter/generator for aero-engine," IEEE Trans. Ind. Electron., vol. 63, no. 1, pp. 641-652, 2016.

[6] W. Cao, B. C. Mecrow, G. J. Atkinson, J. W. Bennett, and D. J. Atkinson, "Overview of electric motor technologies used for more electric aircraft (MEA),"IEEE Trans. Ind. Electron., vol. 59, no. 9, pp. 3523-3531, 2012.

[7] O. Lopez, J. Alvarez, J. Doval-Gandoy, and F. D. Freijedo, "Multilevel Multiphase Space Vector PWM Algorithm With Switching State Redundancy," IEEE Trans. Ind. Electron., vol. 56, no. 3, pp. 792-804, 2009

[8] E. Levi, I. N. W. Satiawan, N. Bodo, and M. Jones, "A space-vector modulation scheme for multilevel open-end winding five-phase drives," IEEE Trans. Energy Convers., vol. 27, no. 1, pp. 1-10, 2012.

[9] G. Carrasco and C. A. Silva, "Space vector PWM method for five-phase two-level VSI with minimum harmonic injection in the overmodulation region," IEEE Trans. Ind. Electron., vol. 60, no. 5, pp. 2042-2053, 2013.

[10] S. M. Ahmed, H. Abu-Rub, and Z. Salam, "Common-mode voltage elimination in a three-to-five-phase dual matrix converter feeding a fivephase open-end drive using space-vector modulation technique," IEEE Trans. Ind. Electron., vol. 62, no. 10, pp. 6051-6063, 2015

[11] N. Bodo, E. Levi, and M. Jones, "Investigation of carrier-based PWM techniques for a five-phase open-end winding drive topology," IEEE Trans. Ind. Electron., vol. 60, no. 5, pp. 2054-2065, 2013.

[12] I. Zoric, M. Jones, and E. Levi, "Arbitrary Power Sharing Among ThreePhase Winding Sets of Multiphase Machines," IEEE Trans. Ind. Electron., vol. 65, no. 2, pp. 1128-1139, 2017.

[13] F. Barrero and M. J. Duran, "Recent advances in the design, modeling, and control of multiphase machines - Part I," IEEE Trans. Ind. Electron., vol. 63, no. 1, pp. 449-458, 2016.

[14] F. Barrero and M. J. Duran, "Recent Advances in the Design, Modeling, and Control of Multiphase Machines - Part II," IEEE Trans. Ind. Electron., vol. 63 , no. 1, pp. 459-468, 2016.

[15] E. Levi, "Advances in converter control and innovative exploitation of additional degrees of freedom for multiphase machines," IEEE Trans. Ind. Electron., vol. 63, no. 1, pp. 433-448, 2016.

[16] D. Gerada, A. Mebarki, N. L. Brown, C. Gerada, A. Cavagnino, and A. Boglietti, "High-speed electrical machines: Technologies, trends, and developments," IEEE Trans. Ind. Electron., vol. 61, no. 6, pp. 2946-2959, 2014.

[17] A. Smirnov, N. Uzhegov, T. Sillanpaa, J. Pyrhonen, and O. Pyrhonen, "High-Speed Electrical Machine with Active Magnetic Bearing System Optimization," IEEE Trans. Ind. Electron., vol. 64, no. 12, pp. 9876-9885, 2017.

[18] Y. Zhang, S. McLoone, W. Cao, F. Qiu, and C. Gerada, "Power Loss and Thermal Analysis of a MW High Speed Permanent Magnet Synchronous Machine," IEEE Trans. Energy Convers., vol. 32, no. 4, pp. 1468-1478, 2017.

[19] M. Van Der Geest, S. Member, H. Polinder, S. Member, J. A. Ferreira, and M. Christmann, "Power Density Limits and Design Trends of HighSpeed Permanent Magnet Synchronous Machines," IEEE Trans. Transp. Electrif., vol. 1, no. 3, pp. 266-276, 2015.

[20] C. Li et al., "A Modified Neutral-Point Balancing Space Vector Modulation Technique for Three-Level Neutral Point Clamped Converters in High Speed Drives," IEEE Trans. Ind. Electron., 2018.

[21] P. Stumpf, R. K. Jardan, and I. Nagy, "Subharmonics Generated by Space Vector Modulation in Ultrahigh Speed Drives," IEEE Trans. Ind. Electron., vol. 59, no. 2, pp. 1029-1037, 2012.

[22] D. Han, Y. Li, and B. Sarlioglu, "Analysis of SiC based power electronic inverters for high speed machines," Conf. Proc. - IEEE Appl. Power Electron. Conf. Expo. - APEC, pp. 304-310, 2015.

[23] M. Merdzan, J. J. H. Paulides, A. Borisavljevic, and E. A. Lomonova, "The influence of the inverter switching frequency on rotor losses in highspeed permanent magnet machines: An experimental study," Proc. - 2015 IEEE Int. Electr. Mach. Drives Conf. IEMDC 2015, pp. 1628-1633, 2016.

[24] K. Basu, J. S. S. Prasad, and G. Narayanan, "Minimization of torque ripple in PWM AC drives," IEEE Trans. Ind. Electron., vol. 56, no. 2, pp. 553$558,2009$.

[25] H.-S. Jung, C.-E. Hwang, H.-S. Kim, S.-K. Sul, H. An, and H. Yoo, "Minimum Torque Ripple Pulse Width Modulation with Reduced Switching Frequency for Medium Voltage Motor Drive," IEEE Trans. Ind. Appl., vol. 54, no. 4, pp. 3315-3325, 2018.

[26] M. Van Der Geest, H. Polinder, and J. A. Ferreira, "Influence of PWM switching frequency on the losses in PM machines," Proc. - 2014 Int. Conf. Electr. Mach. ICEM 2014, pp. 1243-1247, 2014.

[27] Y. Miyama, M. Ishizuka, H. Kometani, and K. Akatsu, "Vibration Reduction by Applying Carrier Phase-Shift PWM on Dual Three-Phase Winding Permanent-Magnet Synchronous Motor," IEEE Trans. Ind. Appl., 2018.

[28] G. Valente, L. Papini, A. Formentini, and C. Gerada, "Radial Force Control of Multi-Sector Permanent Magnet Machines for Vibration Suppression," IEEE Trans. Ind. Electron., vol. 65, no. 7, pp. 5395-5405, 2018.

[29] G. Sala, D. Gerada, C. Gerada, and A. Tani, "Design and control of segmented triple three-phase SPM machines for fault tolerant drives," Proc. - 2017 IEEE Work. Electr. Mach. Des. Control Diagnosis, WEMDCD 2017, pp. 63-68, 2017.

[30] Z. Liu, Z. Zheng, S. D. Sudhoff, C. Gu, and Y. Li, "Reduction of CommonMode Voltage in Multiphase Two-Level Inverters Using SPWM with Phase-Shifted Carriers," IEEE Trans. Power Electron., vol. 31, no. 9, pp. 6631-6645, 2016.

[31] D. G. Holmes and T. A. Lipo, Pulse Width Modulation for Power Converters: Principles and Practice. Hoboken, NJ, USA: Wiley, 2003.

[32] A. Galassini, G. Lo Calzo, A. Formentini, C. Gerada, P. Zanchetta, and A. Costabeber, "UCube: Control platform for power electronics," Proc. 2017 IEEE Work. Electr. Mach. Des. Control Diagnosis, WEMDCD 2017 , pp. 216-221, 2017.

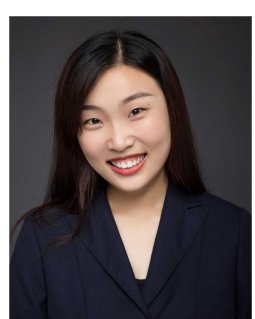

Xuchen Wang (S'19) was born in Taizhou, China, in 1993. She received her B.Eng. (Hons.) degree in electrical and electronic engineering from the University of Nottingham Ningbo China, Ningbo, China, in 2015. She is currently pursuing her Ph.D degree in the Key Laboratory of More Electric Aircraft Technology of Zhejiang Province, University of Nottingham Ningbo China.

Her research interests include design, modelling and control of multiphase drives.

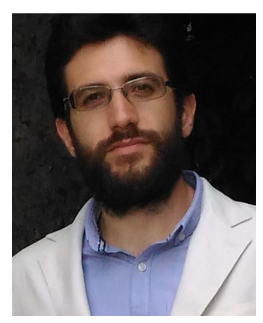

Giacomo Sala was born in Vercelli, Italy, in 1990. He received the B. Sc. in Power Engineering in 2012, the M. Sc. degree with honors in Electrical Engineering in 2014, and the Ph. D. in Electrical Machines and Drives in 2018 from the University of Bologna, Bologna, Italy.

$\mathrm{He}$ was a researcher with the Department of Electrical and Electronic Engineering (PEMC group), at The University of Nottingham, until 2019. He joined the Department of Electric, Electronic and Information Engineering "G.

Marconi," University of Bologna, where he has been a research fellow since 2019. His research interests include design, modelling and control of multiphase machines for high power systems with high performance and reliability requirements. 


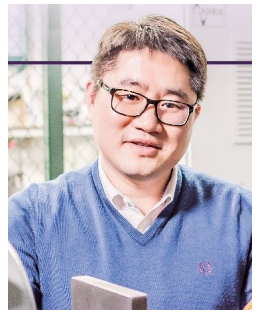

He Zhang (M'14-SM'18) received his B.Eng. degree from Zhejiang University, China, in 2002. $\mathrm{He}$ obtained the MSc. and Ph.D. degree in electrical machines from The University of Nottingham, UK, in 2004 and 2009 respectively.

$\mathrm{He}$ worked as Research Fellow at the University and Director of BestMotion Technology Centre. He moved to University of Nottingham Ningbo China as Senior Research Fellow in 2014 and Principal Research Fellow in 2016. Currently he is the Director of Nottingham Electrification Centre (NEC) within the Power electronics, Machines and Control research group in University Of Nottingham. His research interests include high performance electric machines and drives for transport electrification.

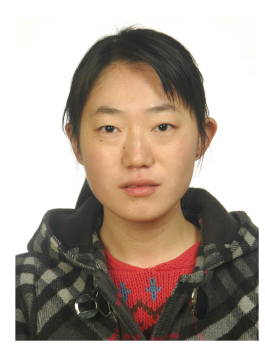

Chunyang Gu (S'12-M'15) was born in Heilongjiang, China, in 1988. She received BSc degree from Harbin Institute of Technology, Harbin, China, in 2010, and PhD degree from Tsinghua University, Beijing, China, in 2015 both in electrical engineering. In 2015, she went to the University of Nottingham, UK, where she was a postdoc research fellow in Power Electronics, Machines and Control (PEMC) Research Group.

Since 2017, she has been an Assistant Professor in Department of Electrical and Electronic Engineering and PEMC Research Group, University of Nottingham Ningbo China. Her research interests include power electronics for transportation electrification, renewable energy and grid applications, e.g. solid-state transformer, solid-state circuit breaker, multi-level converter topologies and control, application of wide-band-gap semiconductor devicespower electronics in EV, railway, marine and MEA.

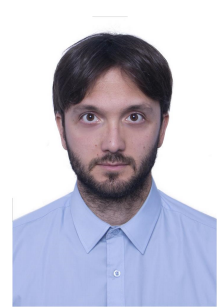

Giampaolo Buticchi (S'10-M'13-SM'17) received the Master degree in Electronic Engineering in 2009 and the PhD degree in Information Technologies in 2013 from the University of Parma, Italy. In 2012, he was visiting researcher at The University of Nottingham, UK. Between 2014 and 2017, he was a post-doctoral researcher and Von Humboldt Postdoctoral Fellow at the University of Kiel, Germany.

$\mathrm{He}$ is now Associate Professor in Electrical Engineering at The University of Nottingham Ningbo China and the Head of Power Electronics of the Nottingham Electrification Center. His research focuses on power electronics for renewable energy systems, smart transformer fed micro-grids and dc grids for the More Electric Aircraft. He is author/co-author of more than 180 scientific papers and an Associate Editor of the IEEE Transactions on Industrial Electronics and of the IEEE Transactions on Transportation Electrification.

Dr. Buticchi is the Chair of the IEEE Industrial Electronics Society Technical Committee on Renewable Energy Systems.

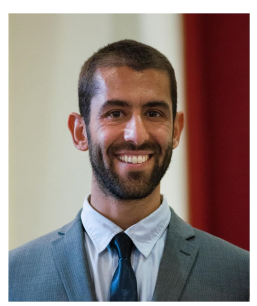

Andrea Formentini (M'16) received the M.S degree in computer engineering and the $\mathrm{PhD}$ degree in electrical engineering from the University of Genova, Genova, in 2010 and 2014 respectively.

He then start working as research fellow in the Power Electronics, Machines and Control Group, University of Nottingham. Since 2018 he is Assistant Professor at University of Nottingham. $\mathrm{His}$ research interests include control of electrical machine drives, power converters and microgrids.

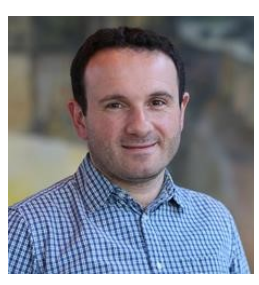

Chris Gerada (M'05-SM'12) received the Ph.D. degree in numerical modelling of electrical machines from The University of Nottingham, Nottingham, U.K., in 2005.

He subsequently worked as a Researcher with The University of Nottingham on highperformance electrical drives and on the design and modelling of electromagnetic actuators for aerospace applications. In 2008, he was appointed as a Lecturer in electrical machines; in 2011, as an Associate Professor; and in 2013, as a Professor at The University of Nottingham. $\mathrm{He}$ was awarded a Research Chair from the Royal Academy of Engineering in 2013. He is an Associate Pro-Vice-Chancellor for Industrial Strategy and Impact and Professor of Electrical Machines. His principal research interest lies in electromagnetic energy conversion in electrical machines and drives, focusing mainly on transport electrification. He has secured over $£ 20 \mathrm{M}$ of funding through major industrial, European and UK grants and authored more than 350 referred publications.

Prof. Gerada served as an Associate Editor for the IEEE TRANSACTIONS ON INDUSTRY APPLICATIONS and is the past Chair of the IEEE IES Electrical Machines Committee.

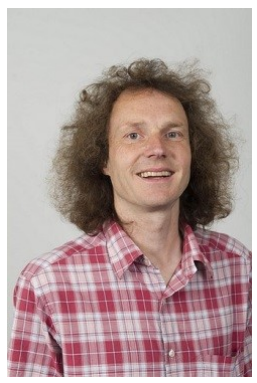

Patrick Wheeler (M'94-SM'08) received his BEng [Hons] degree in 1990 from the University of Bristol, UK. He received his $\mathrm{PhD}$ degree in Electrical Engineering for his work on Matrix Converters from the University of Bristol, UK in 1994.

In 1993 he moved to the University of Nottingham and worked as a research assistant in the Department of Electrical and Electronic Engineering. In 1996 he became a Lecturer in the Power Electronics, Machines and Control Group at the University of Nottingham, UK. Since January 2008 he has been a Full Professor in the same research group. He was Head of the Department of Electrical and Electronic Engineering at the University of Nottingham from 2015 to 2018. He is currently the Head of the Power Electronics, Machines and Control Research Group, Global Director of the University of Nottingham's Institute of Aerospace Technology and is the Li Dak Sum Chair Professor in Electrical and Aerospace Engineering. He has published 500 academic publications in leading international conferences and journals.

Prof. Wheeler is a member of the IEEE PELs AdCom and was an IEEE PELs Distinguished Lecturer from 2013 to 2017. 